\title{
Perancangan Perancangan Boost Converter Pada Mobil Hybrid (Tenaga Angin dan Surya)
}

\author{
Alex Surapati, Irnanda Priyadi, Arya Pramudianto \\ ${ }^{1}$ Program Studi Teknik Elektro Fakultas Teknik Universitas Bengkulu \\ *E-mail: alexsurapati@unib.ac.id
}

\begin{abstract}
The development of the automotive caused an increase in fuel demand and an increase in the price of oil which continues to increase, so more and more industries continue to develop hybrid cars. The use of hybrid cars is very effective and efficient, besides not causing air pollution, the construction is also simpler than other conventional cars. Hybrid cars don't have complicated machines like conventional cars. In this study, a hybrid car requires 48 volt $D C$ power so that it requires 4 batteries connected in series. The solar panel that is used can only provide a maximum voltage of 36 volts DC so that it requires a tool that is able to meet the voltage requirements. This study will produce a DC-DC converter called a boost converter that serves to adjust the source voltage to the voltage needed without having to eliminate relatively large power so that it can overcome the shortage of voltage. Based on this research, the output of a boost converter of 51 volts is obtained for charging batteries from solar panels with the efficiency of the power passed by the boost converter to a maximum of $94 \%$ and minimum efficiency of $77 \%$.
\end{abstract}

Keywords: Hybrid car, Boost Converter, Solar Panel, Battery

•

ABSTRAK

Perkembangan dunia otomotif menyebabkan peningkatan kebutuhan bahan bakar dan kenaikkan harga minyak bumi yang terus meningkat, maka semakin banyak pula industri-industri yang terus mengembangkan mobil hybrid. Penggunaan mobil hybrid sangat efektif dan efisien, selain tidak menimbulkan polusi udara kontruksinya juga lebih sederhana dibandingkan mobil konvensional lainnya. Mobil hybrid tidak memiliki mesin yang rumit seperti mobil konvensional. Dalam penelitian ini, mobil hybrid membutuhkan tenaga 48 volt DC sehingga membutuhkan 4 aki yang terhubung seri. Panel surya yang digunakan hanya dapat memberikan tegangan maksimal sebesar 36 volt DC sehingga membutuhkan alat yang mampu mencukupi kebutuhan tegangan tersebut. Penelitian ini akan menghasilkan sebuah $D C-D C$ converter yang disebut boost converter yang berfungsi untuk menyesuaikan tegangan sumber terhadap tegangan yang diperlukan tanpa harus menghilangkan daya yang relatif besar sehingga dapat mengatasi kekurangan tegangan tersebut. Berdasarkan penelitian ini didapat hasil keluaran boost converter sebesar 51 volt untuk pengisian aki dari panel surya dengan efesiensi daya yang dilewatkan oleh boost converter maksimum sebesar 94\% dan efesiensi minimum sebesar $77 \%$.

Kata kunci: Mobil hybrid, Boost Converter, Panel Surya, Aki

\section{PENDAHULUAN}

Peningkatan kebutuhan bahan bakar fosil bagi kendaraan mengakibatkan sumber energi tersebut semakin menipis. Pemanfaat energi alternatif terbarukan merupakan solusi pengganti energi fosil diantaranya energi angin dan surya. Penggunaan mobil listrik sudah mulai diminati oleh masyarakat sehingga mulai banyak penelitian aplikatif pembuatan mobil listrik. mobil listrik yang dibuat menggunakan panel surya sebagai sumber energi pengisian aki. Panel surya mempunyai besar ukuran yang linier dengan tegangan yang dihasilkannya, sehingga sulit mendapatkan hasil yang efisien dalam penggunaannya. Pengaruh besar ukuran panel surya sangat berdampak saat diaplikasikan pada rancang bangun mobil listrik, sehingga pemilihan panel surya menjadi faktor penting yang mendasari ukuran dari rancang bangun mobil listrik.

Panel surya juga selalu dikaitkan dalam pengisian dari aki sebagai sumber penyimpanan listrik DC, dimana aki merupakan salah satu piranti utama dalam

penyimpanan sumber energi listrik DC. Aki yang digunakan pada umumnya memiliki voltase sebesar 12 volt DC, namun banyak juga beban yang mengharuskan voltase diatas 12 volt DC sebagai suplainya sehingga biasanya dibutuhkan beberapa aki yang dihubung seri untuk mencukupi kebutuhan tegangan yang diperlukan oleh beban.

Dalam penelitian ini, mobil listrik membutuhkan tenaga 48 volt DC sehingga membutuhkan 4 aki yang terhubung seri. Panel surya yang digunakan hanya dapat 


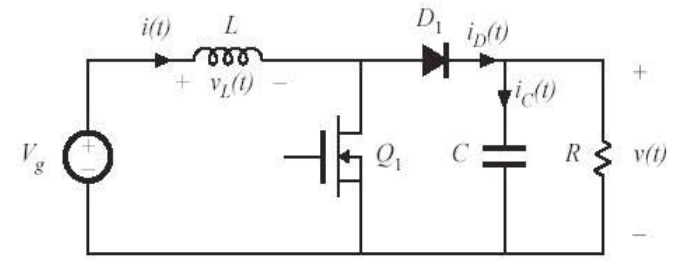

Gambar 1 Skema Konverter Penaik Tegangan[1].

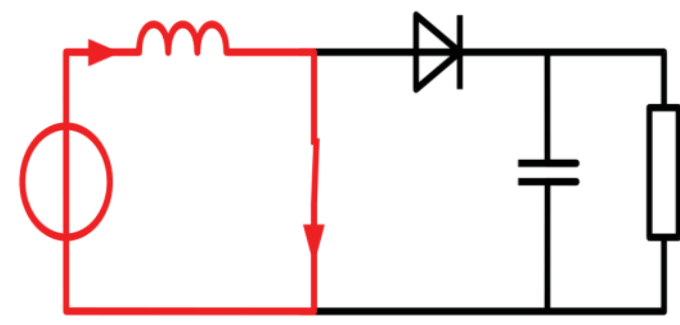

Gambar 2. Skema Prinsip Kerja Konverter Penaik Tegangan Saat Saklar toff [1].

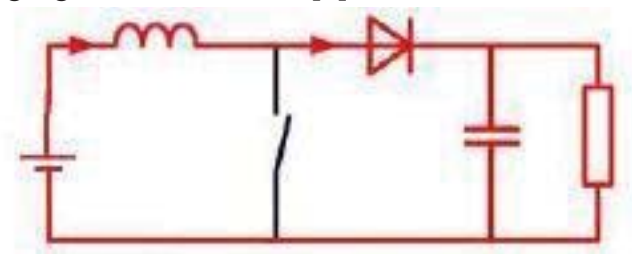

Gambar 3 Skema Prinsip Kerja Konverter Penaik

memberikan tegangan maksimal sebesar 36 volt DC sehingga membutuhkan alat yang mampu mencukupi kebutuhan tegangan tersebut. Kondisi ketidaksesuaian antara tegangan yang dihasilkan panel surya dengan besarnya kebutuhan tegangan dalam pengisianaki menjadi masalah utama. Tujuan penelitian ini adalah merancang sebuah $D C-D C$ converter yang disebut boost converter yang berfungsi untuk menyesuaikan tegangan sumber terhadap tegangan yang diperlukan tanpa harus menghilangkan daya yang relatif besar sehingga dapat mengatasi kekurangan tegangan.

\section{KERANGKA TEORITIS DAN PENGEMBANGAN HIPOTESIS}

Konverter arus searah ke arus searah (DC to $D C$ Converter) adalah peralatan yang dapat mengubah tegangan pada sistem arus searah dari nilai tertentu ke nilai yang lain. Nilai yang diubah pada umumnya menjadi lebih besar ataupun lebih kecil dari nilai sebelumnya. Konverter DC-DC biasanya digunakan untuk aplikasi beterai dan mesin-mesin yang membutuhkan tegangan arus searah yang variabel [8]. Penggunaan Konverter DC-DC memungkinkan untuk penghemat penggunaan baterai jika membutuhkan nilai tegangan tertentu.
Konverter penaik tegangan (boost converter) adalah salah satu topologi $D C$-DC converter yang digunakan untuk menaikkan tegangan DC. Rangkaian ini digunakan ketika dibutuhkan tegangan keluaran yang lebih besar daripada tegangan masukannya. Komponen utama pada topologi ini adalah induktor, kapasitor, diode, dan switch (MOSFET) [6]. Rangkaian dari Konverter penaik tegangan dapat dilihat pada Gambar 1 .

Tegangan Saat Saklar ton[1].

Dari skema sistem kerja penaik tegangan terdapat 2 kondisi yaitu pada saklar on dan saklar pada posisi off. Hal ini terjadi dikarenakan mosfet bekerja berdasarkan sinyal yang diberikan kepadanya. Pada kondisi ini mosfet bekerjberdasarkan sinyal duty cycle dengan perumusan atau perhitungan berdasarkan persamaan berikut :

$\mathrm{Vo}=\frac{V s}{1-D}$

Adapun faktor-faktor pemilih komponen dalam rangkaian boost converte dengan menggunakan persamaanpersamaan berikut:[5]

$\Delta \mathrm{IL}=0,4 \times$ Iout $\times\left(\frac{\text { Vout }+V f}{\text { Vin }}\right)$

$\mathrm{L}=\frac{1}{f} \times($ Vout $+\mathrm{Vf}-\mathrm{Vin}) \times\left(\frac{1}{\Delta I l}\right)$

Dimana:

$\mathrm{L}=$ Induktansi inductor

$\mathrm{Vo}_{\mathrm{o}}=$ Tegangan output

Vin $=$ Tegangan input

$\mathrm{f}=$ Frekuensi switching

$\Delta \mathrm{IL}=$ Ripple arus

Setelah melakukan perhitungan dengan persamaan di atas, maka dapat diperoleh nilai induktor yang sesuai dengan target perancangan. Untuk mendapatkan nilai kapasitor yang sesuai dapat dilakukan perhitungan menggunakan persamaan berikut ini:[5]

IDpeak $=\frac{I o}{D}$

IDrms $=$ IDpeak $\mathrm{x} v \sqrt{D}$

$\mathrm{Icrms}=\sqrt{I D r m s^{2}-I o^{2}}$

$\mathrm{C}=\frac{\operatorname{Icrms} \times D \times T}{\Delta V o}$

Dimana:

$\mathrm{C}=$ kapasitansi kapasitor

Icrms = arus RMS capasitor

$\Delta \mathrm{Vo}_{\mathrm{o}}=$ ripple tegangan

$\mathrm{D}=$ duty cycle

$\mathrm{T}=$ periode

Untuk daya yang masukan dan keluaran yang dihasilkan dari penaiktegangan dapat dirumuskan menggunakan persamaan berikut: 


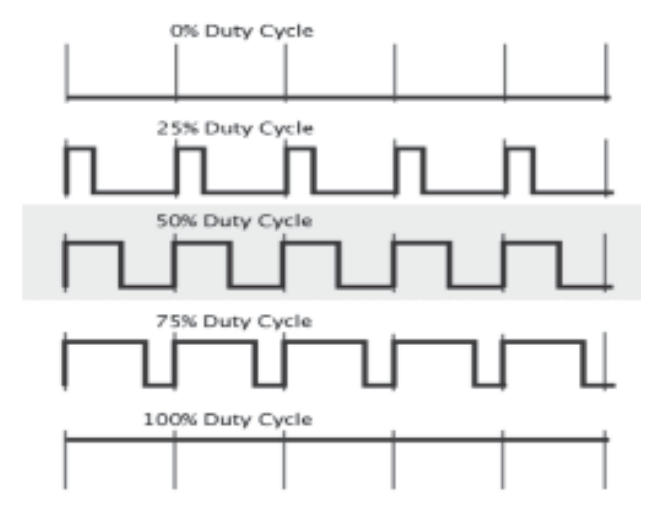

Gambar 4. Sinyal Duty cycle[14].

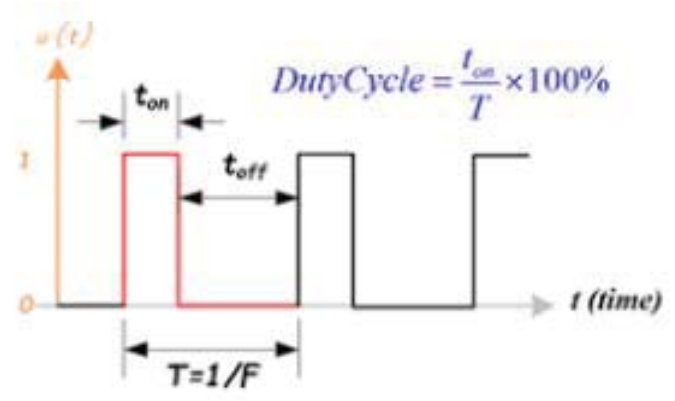

Gambar 5. Karateristik Duty cycle[7].

$(\mathrm{Ps}=\mathrm{Po})[1]$

\section{A. PWM (Pulse Width Modulation)}

PWM (Pulse Width Modulation) adalah salah satu teknik modulasi dengan mengubah lebar pulsa (duty cylce) dengan nilai amplitudo dan frekuensi yang tetap. Satu siklus pulsa merupakan kondisi high kemudian berada di zona transisi ke kondisi low. Lebar pulsa PWM berbanding lurus dengan amplitudo sinyal asli yang belum termodulasi. Duty Cycle merupakan representasi dari kondisi logika high dalam suatu periode sinyal dan di nyatakan dalam bentuk (\%) dengan range $0 \%$ sampai $100 \%$, sebagai contoh jika sinyal berada dalam kondisi high terus menerus artinya memiliki duty cycle sebesar $100 \%$. Jika waktu sinyal keadaan high sama dengan keadaan low maka sinyal mempunyai duty cycle sebesar $50 \%$.

Dari Gambar 5 Dapat dilihat bahawa duty cycle dapat diatur berdasarkan besar dari Th dan TL. Adapun perhitungan untuk mendapatkan atau mengatur duty cycle dengan menggunakan persamaan berikut:

$\mathrm{T}=\frac{1}{f}$

$\mathrm{TL}=0,693 \times \mathrm{RB} \times \mathrm{C}$

$\mathrm{Th}=0,693 \times(\mathrm{RA}+\mathrm{RB}) \times \mathrm{C}$

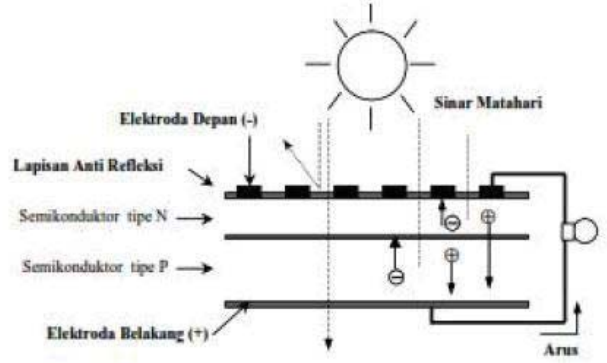

Gambar 6. Proses pengubahan energi matahari menjadi energi listrik pada sel surya[2].

$\mathrm{T}=\mathrm{TH}+\mathrm{TL}$

$\mathrm{D}=\frac{\text { Ton }}{\text { Ton+Toff }} \times 100 \%$

Dimana :

$0,693=$ Konstanta ketetapan

Ton $=$ Kondisi hidup

Toff $=$ Kondisi mati

RB $=$ Hambatan pembagi

$\mathrm{RA}=$ Hambatan Seri

$\mathrm{C}=$ Kapasitor

$\mathrm{D}=$ Duty cycle

\section{B. Sel surya}

Panel surya terdiri dari beberapa sel surya yang disusun sedemikian rupa sehingga didapatkan output sesuai dengan yang diinginkan. Dari kumpulan sel surya ini dapat dikonversi cahaya matahari menjadi listrik arus searah. Dengan menambahkan baterai yang dihubungkan dengan panel surya, maka daya hasil konversi cahaya matahari menjadi listrik dapat disimpan sebagai cadangan energi listrik. Secara sederhana sel surya terdiri dari persambungan bahan semikonduktor bertipe $\mathrm{p}$ dan $\mathrm{n}$ ( $p-n$ junction semiconductor) yang jika terkena sinar matahari maka akan terjadi aliran elektron, aliran elektron inilah yang disebut sebagai aliran arus listrik. Proses pengubahan energi matahari menjadi energi listrik ditunjukkan dalam Gambar 6.

Bagian utama pengubah energi sinar matahari menjadi listrik adalah penyerap (absorber), meskipun demikian masing-masing lapisan juga sangat berpengaruh terhadap efisiensi dari sel surya. Sinar matahari terdiri dari bermacam-macam jenis gelombang elektromagnetik, oleh karena itu penyerap disini diharapkan dapat menyerap sebanyak mungkin radiasi sinar yang berasal dari cahaya matahari[2].

\section{Baterai}

Baterai adalah sebuah peralatan yang dapat mengubah energi kimia yang terkandung dalam material aktif menjadi energi listrik. Baterai terdiri dari beberapa sel yang disusun secara seri menjadi sebuah baterai. Sel 


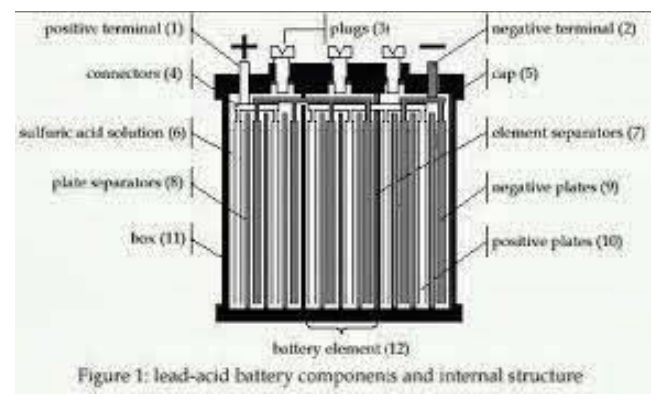

Gambar 7. Komponen Utama Baterai[4].

merupakan elemen dasar elektronika yang digunakan untuk menyimpan energi. Beterai terdiri dari dua jenis, yaitu baterai primer dan baterai sekunder.

Baterai primer merupakan baterai yang hanya dapat digunakan sekali dan tidak dapat diisi ulang. Baterai ini hanya dapat digunakan sekali saja karena reaksi kimia yang ada di dalam material aktifnya tidak dapat dikembalikan. Contoh baterai zinccarbon baterai alkalin, dll. Baterai primer memiliki keunggulan dalam harga dan memiliki kerapatan energi yang tinggi. Baterai sekunder adalah baterai yang dapat diisi ulang. Beterai sekunder dapat diisi ulang karena reaksi kimia di dalam material aktifnya dapat diputar kembali. Kelebihan dari baterai sekunder adalah harganya lebih efisien untuk penggunaan jangka panjang. Contoh baterai lead-acid, baterai $\mathrm{NiCd}$, baterai $\mathrm{NiMH}$, dll.

\section{METODE RISET}

Pada penelitian ini rancangan sistem terbagi menjadi 2 bagian, yang pertama adalah sistem penstabil tegangan yang berguna untuk menstabilkan tegangan yang diberikan oleh panel surya. Bagian kedua merupakan penaik tegangan yang didapati dari panel surya kemudian dinaikkan untuk mendapatkan tegangan ideal untuk proses pengisian aki. Hal ini dilakukan karena panel surya yang dipakai memiliki keluaran tegangan yang tidak mencukupi untuk melakukan pengisian aki. Pada perancangan penaik tegangan atau Boost Converter ini sangat bergantung

pada penyesuaian besarnya duty cycle, besarnya duty cycle akan mempengaruhi rasio perbandingan tegangan input dan output pada boost converter. Pemilihan komponen yang akan digunakan jugamenjadi faktorfaktor yang sangat penting dalam perancangan yang dilakukan.

Penentuan besarnya komponen yang dipakai sebelumnya telah diperhitungkan dahulu dengan menggunakan persamaan-persamaan yang telah diuraikan pada bab sebelumnya. Proses pengamatan dan pengambilan data dilakukan dengan menggunakan

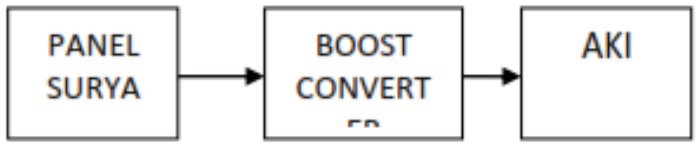

Gambar 8. Diagram blok sistem pengisian aki menggunakan boost converter

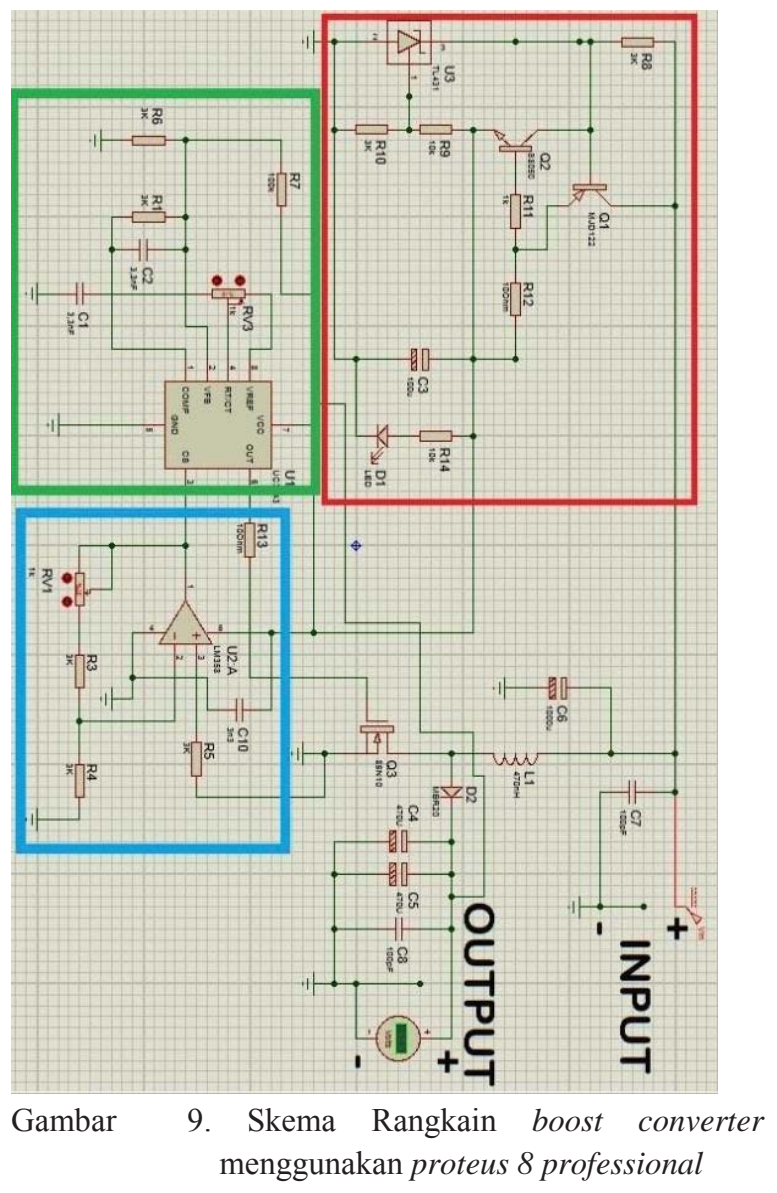

alat ukur yang dipasang pada input dan output pada boost converter. Alat ukur yang dipakai untuk melihat tegangan dan arus yang melewati boost converter. Daya yang masuk dan keluar pada alat ini kemudian akan dilihat perbandingannya guna melihat efesiensi dari rangkaian yang dirancang.

Boost converter ini dirancang secara analog. Tegangan keluaran dari boost converter ini dapat divariasikan dengan mengatur resistor variabel yang dibuat untuk menyesuaikan tegangan ideal yang diinginkan pada proses pengisian aki. Tegangan ideal pada pengisian menjadi faktor yang paling dijaga pada rancangan ini, dimana tegangan ini akan menyesuaikan dengan tegangan dari aki yang semakin bertambah seiring dengan semakin lamanya proses pengisian yang diberikan dari panel surya. 


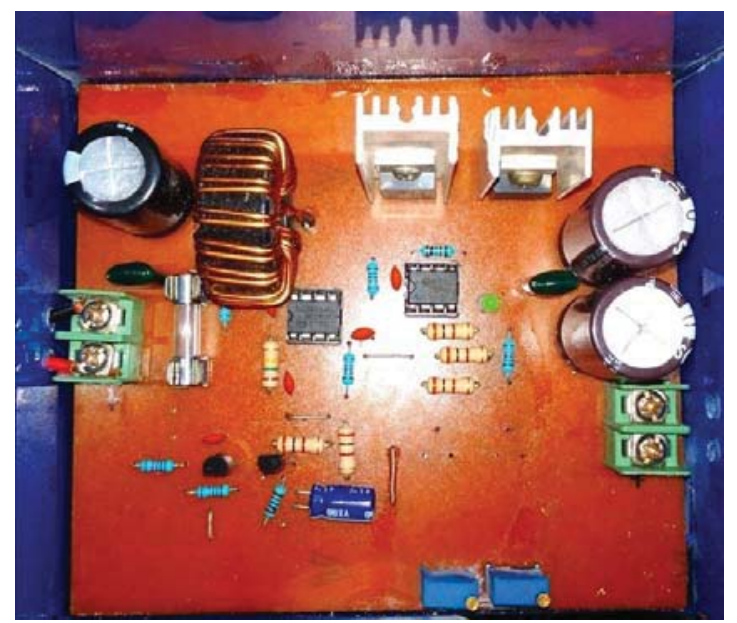

Gambar 10. Hasil perancangan boost converter

Rancangan sistem penaik tegangan ini akan bekerja dengan rating $>48$ volt, dengan input yang diberikan dari panel surya yang memberikan tegangan maksimal sebesar 36 volt. Arus dan tegangan yang diberikan panel surya tidak konstan dan sangat bergantung pada cuaca sehingga penelitian ini juga merancang penstabil tegangan. Untuk lebih jelas mengenai keseluruhan kerja sistem secara umum dapat dilihat pada Gambar 8.

\section{HASIL DAN PEMBAHASAN}

Pada tahap ini dilakukan pengujian terhadap hasil rangkaian boost converter untuk mengetahui hasil dari rancangan yang telah dilakukan. Adapun hasil dari perancangan boost converter dapat dilihat pada Gambar 10.

\section{A. Analisa pengaruh duty cycle pada perubahan tegangan.}

Pada perancangan ini, hal yang paling menentukan duty cycle yaitu faktor resistor variabel. Dalam perancangan resistor variabel terhubung seri terhadap kapasitor dan dihubungkan pada masukan RT/CT pada IC UC3843 yang merupakan osilator pada IC tersebut. Pengisian dan pengosongan pada kapasitor menjadi faktor terbentuknya perioda yang kemudian diolah pada IC tersebut. proses dibentuknya dutycycle dengan perhitungan sebagai berikut: (Diketahui frekuensi pada datasheet IC UC3843 sebesar 500kHz).

Dimana: $\mathrm{R}=\mathrm{Rv}=600 \mathrm{Ohm}, \mathrm{C}=3,3 \mathrm{nF}$

Perhitungan perioda :

$\mathrm{T}=\frac{1}{500 \mathrm{kHz}}=2 \mu \mathrm{S}$

$\mathrm{T}=\mathrm{TH}+\mathrm{TL}$

Perhitungan perioda Low :

$\mathrm{TL}=0,693 \times \mathrm{R} \times \mathrm{C}$
TABEL 1

HASIL PENGUKURAN KELUARAN TEGANGAN PANEL SURYA

\begin{tabular}{|l|l|l|l|}
\hline Data & $\begin{array}{l}\text { Waktu } \\
\text { (WIB) }\end{array}$ & $\begin{array}{l}\text { Suhu } \\
\left({ }^{\circ} \mathrm{C}\right)\end{array}$ & $\begin{array}{l}\text { Tegangan } \\
\text { keluaran } \\
\text { panel surya } \\
\text { (volt) }\end{array}$ \\
\hline 1 & 07.00 & 34 & 12,5 \\
\hline 2 & 07.30 & 35 & 12 \\
\hline 3 & 08.00 & 40 & 18 \\
\hline 4 & 08.30 & 41 & 17,5 \\
\hline 5 & 09.00 & 43 & 32 \\
\hline 6 & 09.30 & 45 & 32 \\
\hline 7 & 10.00 & 46 & 34 \\
\hline 8 & 10.30 & 46 & 35 \\
\hline 9 & 11.00 & 47 & 35 \\
\hline 10 & 11.30 & 47 & 35 \\
\hline 11 & 12.00 & 47 & 35 \\
\hline
\end{tabular}

\begin{tabular}{|l|l|l|l|}
\hline 12 & 12.30 & 46 & 35 \\
\hline 13 & 13.00 & 45 & 33 \\
\hline 14 & 13.30 & 43 & 33 \\
\hline 15 & 14.00 & 42 & 32 \\
\hline 16 & 14.30 & 42 & 30 \\
\hline 17 & 15.00 & 41 & 27 \\
\hline 18 & 15.30 & 38 & 34 \\
\hline 19 & 16.00 & 38 & 33,5 \\
\hline 20 & 16.30 & 37 & 30,5 \\
\hline 21 & 17.00 & 30 & 13 \\
\hline 22 & 17.30 & 29 & 13 \\
\hline 23 & 18.00 & 27 & 9 \\
\hline
\end{tabular}

$=0,693 \times 600 \mathrm{Ohm} \times 3,3 \mathrm{nF}$

$$
=1,3 \mu \mathrm{S}
$$

Perhitungan perioda high :

$\mathrm{Th}=\mathrm{T}-\mathrm{TL}$

$=2 \mu \mathrm{S}-1,3 \mu \mathrm{S}=0,7 \mu \mathrm{S}$

Perhitungan duty cycle :

$\mathrm{D}=\frac{T h}{T}=\frac{0.7 \mu \mathrm{s}}{2 \mu \mathrm{s}}=0,35=35 \%$

Pada rangkaian PWM ini duty cycle dapat diciptakan dengan mengatur resistor variabel yang telah dirancang. Resistor variabel tersebut mempengaruhi proses pembuatan PWM dengan terhubung langsung pada osilator yang terdapat pada IC UC3843.

Data 1: Vin $=32$ Volt, Vout $=51$ Volt

Perhitungan duty cycle :

$\mathrm{D}=1-\frac{\text { Vin }}{\text { Vout }}=1-\frac{32}{51}=0,37=37 \%$

Perhitungan perioda high :

$\mathrm{Th}=\mathrm{D} \times \mathrm{T}=0,37 \times 2 \mu \mathrm{S}=0,74$

Perhitungan perioda low:

$\mathrm{TL}=\mathrm{T}-\mathrm{Th}=2-0,74=1,26 \mu \mathrm{S}$

Perhitungan resistor variabel :

$\mathrm{TL}=0,693 \times \mathrm{R} \times \mathrm{C}$ 
TABEL 2

HASIL PENGUKURAN TEGANGAN TELUARAN BOOSTCONVERTER TANPA BEBAN

\begin{tabular}{|c|c|c|c|}
\hline $\begin{array}{l}\text { Waktu } \\
\text { (WIB) }\end{array}$ & \begin{tabular}{|l} 
Tegangan \\
keluaran \\
panel \\
surya \\
(volt)
\end{tabular} & $\begin{array}{l}\text { Tegangan } \\
\text { keluaran } \\
\text { boost } \\
\text { converter } \\
\text { (volt) }\end{array}$ & $\begin{array}{l}\text { Keterangan } \\
\text { cuaca }\end{array}$ \\
\hline 07.00 & 12,5 & 51 & Berawan \\
\hline 07.30 & 12 & 51 & Berawan \\
\hline 08.00 & 18 & 51 & Cerah \\
\hline 08.30 & 17,5 & 51 & Berawan \\
\hline 09.00 & 32 & 51 & Cerah \\
\hline 09.30 & 32 & 51 & Berawan \\
\hline 10.00 & 34 & 51 & Cerah \\
\hline 10.30 & 35 & 51 & Cerah \\
\hline 11.00 & 35 & 51 & Cerah \\
\hline 11.30 & 35 & 51 & Cerah \\
\hline 12.00 & 35 & 51 & Cerah \\
\hline 12.30 & 35 & 51 & Cerah \\
\hline 13.00 & 33 & 51 & Cerah \\
\hline 13.30 & 33 & 51 & Cerah \\
\hline 14.00 & 32 & 51 & Cerah \\
\hline 14.30 & 30 & 51 & Cerah \\
\hline 15.00 & 27 & 51 & Berawan \\
\hline 15.30 & 34 & 51 & Cerah \\
\hline 16.00 & 33,5 & 51 & Cerah \\
\hline 16.30 & 30,5 & 51 & Cerah \\
\hline 17.00 & 13 & 51 & Berawan \\
\hline 17.30 & 13 & 51 & Berawan \\
\hline 18.00 & 9 & 0 & Berawan \\
\hline
\end{tabular}

$\mathrm{R}=\frac{T L}{693.0 \times \mathrm{C}}=\frac{1.26 \mu \mathrm{s}}{0.693 \times 3.3 \mathrm{nF}}=550 \mathrm{Ohm}$

Dari perhitungan berdasarkan data ke-1 dimana diketahui hasil duty cycle sebesar 37\%, maka dapat diketahui resistor variabel tersebut berada pada posisi $550 \mathrm{Ohm}$.

\section{B. Pengujian tegangan keluaran panel surya/tegangan masukan boost converter}

Pengujian tegangan keluaran panel surya dilakukan untuk mendapatkan nilai tegangan masukan dari boost converter. Pengujian dilakukan pada kondisi cuaca cerah. Hal ini bertujuan untuk mendapatkan pengaruh sel surya terhadap keluaran panel surya. Hasil pengukuran tegangan keluaran panel surya ditunjukkan pada Tabel 1 .

Berdasarkan data yang ditunjukkan pada Tabel 1 tegangan keluaran maksimum yang dihasilkan oleh panel surya adalah 35 volt dengan kondisi suhu panel surya $47\left({ }^{\circ} \mathrm{C}\right)$ dan tegangan keluaran minimum sebesar 9 volt dengan kondisi suhu $27\left({ }^{\circ} \mathrm{C}\right)$.

\section{Pengujian tegangan keluaran boost converter tanpa beban}

Pengujian tegangan keluaran boostconverter tanpa beban yang dilakukan dengan tujuan untuk melihat pengaruh hasil tegangan yang dihasilkan boost converter dengan menggunakan tegangan panel surya sebagai inputnya. Pengujian dilakukan dengan cara menghubungkan panel surya dengan titik masukan dari rangkaian boost converter yang telah dirancang. Hasil pengukuran tegangan keluaran converter tanpa beban ditunjukkan pada Tabel 2.

Berdasarkan hasil pengukuran tegangan keluaran boost converter tanpa beban pada Tabel 2, dapat dilihat bahwa tegangan keluaran yang dihasilkan oleh rangkaian boost converter yang telah dirancang mendapati hasil yang konstan yaitu 51 volt meskipun dengan tegangan input yang berubah-ubah. Percobaan ini dilakukan untuk mengetahui bagaimana hasil perancangan terhadap waktu percobaan. Dari data Tabel 2 juga terlihat hasil pengujian yang dilakukan didapati tegangan yang berubah-ubah sesuai cuaca dan pada pengujian pukul 18.00 WIB boostconverter tidak dapat lagi menaikkan tegangan dikarenakan tegangan tidak mencukupi lagi untuk mengoperasikan boost converter yang memiliki rating tegangan kerja minimum sebesar 12 volt.

\section{Pengujian tegangan keluaran boostconverter dengan menggunakanbeban aki 48 volt}

Pada tahap ini dilakukan pengujian dengan beberapa variasi tegangan guna mendapatkan tegangan ideal untuk proses pengisian aki yang digunakan pada mobil hybrid dengan sumber tegangan yang didapat dari panel surya. Aki yang digunakan pada mobil hybrid adalah aki 12 Volt 12 Ah yang tersusun seri sebanyak 4 buah sehingga sumber daya dari aki tersebut menjadi 48 Volt 12 Ah, sedangkan panel surya mempunyai tegangan maksimum yang dapat dihasilkan sebesar 36 Volt Ketidaksetimbangan inilah yang menjadikan dibuatnya perancangan ini agar mencukupi proses dalam pengisian aki dari panel surya. 
TABEL 3

HASIL TEGANGAN DAN ARUS PADA PHOTO VOLTAIC (PV) DAN BOOST CONVERTER (BC)

\begin{tabular}{|l|l|l|l|l|}
\hline $\begin{array}{l}\text { Waktu } \\
\text { (WIB) }\end{array}$ & $\begin{array}{l}\text { Tegangan } \\
\text { PV (V) }\end{array}$ & $\begin{array}{l}\text { Arus } \\
\text { (A) }\end{array}$ & $\begin{array}{l}\text { Tegangan } \\
\text { BC (V) }\end{array}$ & $\begin{array}{l}\text { Arus } \\
\text { BC } \\
(\mathrm{A})\end{array}$ \\
\hline 07.00 & 12,5 & 1,63 & 49 & 0,39 \\
\hline 07.30 & 12 & 1,94 & 49 & 0,44 \\
\hline 08.00 & 18 & 2,78 & 49 & 0,61 \\
\hline 08.30 & 17,5 & 2,2 & 49 & 0,74 \\
\hline $09: 00$ & 32 & 2,88 & 49 & 1,77 \\
\hline 09.30 & 32 & 2,81 & 50 & 1,73 \\
\hline $10: 00$ & 34 & 2,75 & 51 & 1,71 \\
\hline 10.30 & 35 & 2,72 & 51 & 1,68 \\
\hline $11: 00$ & 35 & 2,65 & 51 & 1,63 \\
\hline 11.30 & 35 & 2,43 & 52 & 1,44 \\
\hline $12: 00$ & 35 & 2,22 & 52 & 1,36 \\
\hline 12.30 & 35 & 1,96 & 52 & 1,12 \\
\hline $13: 00$ & 33 & 1,6 & 52 & 0,91 \\
\hline 13.30 & 33 & 1,51 & 52 & 0,87 \\
\hline $14: 00$ & 32 & 1,36 & 52 & 0,72 \\
\hline 14.30 & 30 & 1,32 & 52 & 0,64 \\
\hline $15: 00$ & 27 & 1,2 & 52 & 0,53 \\
\hline & & & & \\
\hline
\end{tabular}

Dari Tabel 3 dapat dilihat hasil dari pengambilan data dari boost converter dengan masukan dari panel surya $250 \mathrm{Wp}$ terhadap pengisian aki pada mobil hybrid. Pengambilan data dilakukan dengan cuaca yang cerahberawan. Dari data tersebut

dapat dilihat hasil yang naik turun sesuai dengan pengaruh cuaca yang terjadi pada saat pengambilan data. Tegangan terbesar yang didapat dari panel surya terjadi mulai pukul 10.30 yaitu sebesar 35 Volt. Pada arus yang dihasilkan dari PV didapat hasil arus yang semakin menurun, hal ini disebabkan oleh kapasitas arus pada aki yang semakin bertambah selama proses pengisian.

\section{E. Pengujian daya masukan terhadap daya keluaran}

Daya masukan dan keluaran pada boost converter akan sangat bergantung dari perhitungan dan pemilihan komponen yang digunakan, semakin bagus komponen dan rangkaian yang digunakan maka akan semakin optimal hasil yang didapat. Pada

pengujian daya ini, berlaku persamaan Ps $=$ Po yang dapat dilihat pada landasan teori, yang berarti daya masukan akan sama dengan daya akan dikeluarkan. Berdasarkan persamaan yang didapat pada landasan 26
TABEL 4

HASIL DATA DAYA MASUKAN DAN KELUARAN BOOST CONVERTER

\begin{tabular}{|c|c|c|c|}
\hline $\begin{array}{l}\mathrm{Da} \\
\mathrm{ta}\end{array}$ & $\begin{array}{l}\text { Waktu } \\
\text { (WIB) }\end{array}$ & $\begin{array}{l}\text { Daya masukan } \\
\text { (W) }\end{array}$ & $\begin{array}{l}\text { Daya } \\
\text { keluaran (W) }\end{array}$ \\
\hline 1 & 07.00 & 20,37 & 19,21 \\
\hline 2 & 07.30 & 23,28 & 21,86 \\
\hline 3 & 08.00 & 32,04 & 30,2 \\
\hline 4 & 08.30 & 38,5 & 36,29 \\
\hline 5 & $9: 00$ & 92,16 & 86,73 \\
\hline 6 & $9: 30$ & 89,92 & 86,5 \\
\hline 7 & 10:00 & 93,5 & 87,21 \\
\hline 8 & $10: 30$ & 95,2 & 85,68 \\
\hline 9 & $11: 00$ & 92,75 & 83,13 \\
\hline 10 & $11: 30$ & 85,05 & 74,88 \\
\hline 11 & $12: 00$ & 77,7 & 70,72 \\
\hline 12 & $12: 30$ & 68,6 & 58,24 \\
\hline 13 & $13: 00$ & 52,8 & 47,32 \\
\hline 14 & $13: 30$ & 49,83 & 45,24 \\
\hline 15 & $14: 00$ & 43,52 & 37,44 \\
\hline 16 & $14: 30$ & 39,6 & 33,28 \\
\hline 17 & $15: 00$ & 33,75 & 27,56 \\
\hline 18 & 15.30 & 35,7 & 28,66 \\
\hline 19 & 16.00 & 36,18 & 28,96 \\
\hline 20 & 16.30 & 32,94 & 26,1 \\
\hline 21 & 17.00 & 3,64 & 2,88 \\
\hline 22 & 17.30 & 1,82 & 1,41 \\
\hline 23 & 18.00 & 0,18 & 0 \\
\hline
\end{tabular}

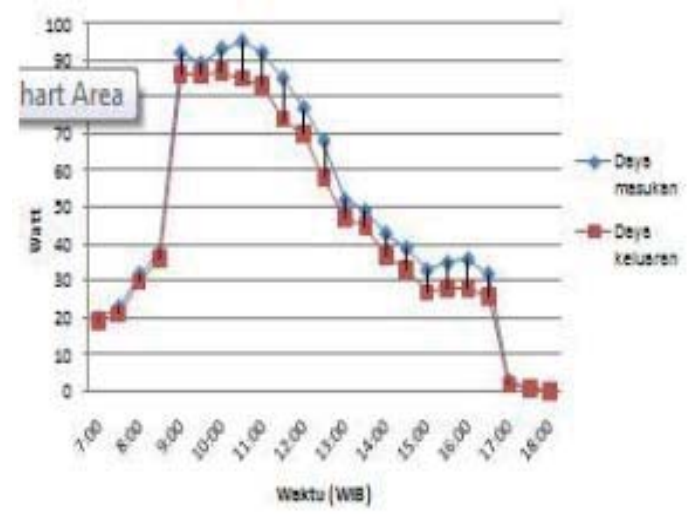

Gambar 11. Grafik perbandingan daya masukan dan keluaran boost converter

teori, dimana VsIs = VoIo maka dilakukan perhitungan guna mandapatkan hasil perbandingan dan hasil kerja dari rangkaian yang telah dilakukan.

VsIs $=$ VoIo

Dari Tabel 4 hasil pengambilan data daya masukan dan keluaran dari boostconverter terlihat daya yang semakin menurun terhadap lamanya proses pengisian

aki, hal ini dikarenakan proses pengisian aki mendekati penuh atau tercukupi. Namun pada data pengukuran didapati daya yang berubah-ubah seusai dengan kondisi 
TABEL 5

DATA HASIL RALAT PERBANDINGAN DAYA MASUKAN DAN KELUARAN BOOST CONVERTER

\begin{tabular}{|l|l|l|l|}
\hline $\begin{array}{l}\text { Daya } \\
\text { masukan } \\
\text { boost } \\
\text { converter } \\
\text { (W) }\end{array}$ & $\begin{array}{l}\text { Daya } \\
\text { keluaran } \\
\text { converter } \\
\text { (W) }\end{array}$ & $\begin{array}{l}\text { Ralat } \\
\text { Mutlak }\end{array}$ & $\begin{array}{l}\text { Ralat } \\
\text { Relatif } \\
(\%)\end{array}$ \\
\hline 20,37 & 19,21 & 1,16 & 94,3 \\
\hline 23,28 & 21,86 & 1,42 & 94 \\
\hline 32,04 & 30,2 & 1,84 & 94,2 \\
\hline 38,5 & 36,29 & 2,21 & 94,2 \\
\hline 92,16 & 86,73 & 5,43 & 94,1 \\
\hline 89,92 & 83,96 & 5,96 & 93,73 \\
\hline 93,5 & 87,21 & 6,29 & 93,27 \\
\hline 95,2 & 85,68 & 9,52 & 90 \\
\hline 92,75 & 83,13 & 9,62 & 89,62 \\
\hline 85,05 & 74,88 & 10,17 & 88,04 \\
\hline 77,7 & 70,72 & 6,98 & 91,01 \\
\hline 68,6 & 58,24 & 10,36 & 84,89 \\
\hline 52,8 & 47,32 & 5,48 & 89,6 \\
\hline 49,83 & 43,16 & 6,67 & 86,61 \\
\hline 43,52 & 37,44 & 6,08 & 86,65 \\
\hline 39,6 & 33,28 & 6,32 & 84,04 \\
\hline 33,75 & 27,56 & 6,19 & 81,65 \\
\hline 35,7 & 28,66 & 7,04 & 80,28 \\
\hline 36,18 & 28,96 & 7,22 & 80 \\
\hline 32,94 & 26,1 & 6,84 & 79,23 \\
\hline 3,64 & 2,88 & 0,76 & 79,1 \\
\hline 1,82 & 1,41 & 0,41 & 77,47 \\
\hline 0,18 & 0 & 0 & 0 \\
\hline
\end{tabular}

cuaca yang terjadi pada saat pengukuran, sehingga itensitas cahaya yang diberikan oleh matahari juga berubah-ubah seusai dengan cuaca dan pada dari Tabel 4 juga terlihat perbedaan antara daya masukan dan keluaran yang sedikit berbeda, hal ini terjadi karena adanya faktor rugi daya yang hilang pada proses pengisian dan juga faktor dari rangkaian boost converter yang digunakan. Perbedaan antara daya masukan dan keluaran dapat dilihat pada Gambar 11.

Dari Gambar 11. Grafik perbandingan daya keluaran dan masukan pada boost converter terlihat pada garis merah merupakan grafik dari daya masukan dan garis biru merupakan grafik daya keluaran. Dari grafik tersebut terlihat perbandingan antara daya keluaran dan masukan yang sedikit berbeda.

Dari Tabel 5 data hasil perhitungan ralat perbandingan daya masukan dan keluaran boost converter dapat dilihat hasil dengan persentase terbesar pada data ke-1 dan persentase terkecil pada data ke-22, hal ini disebabkan oleh kondisi pada saat

diambilnya data pertama boost converter masih pada kondisi yang sangat baik namun seiring dengan digunakan terus-menerus dan tingkat panas pada boost converter yang semakin tinggi sehingga membuat rugirugi semakin banyak dan membuat daya semakin berkurang.

\section{PENUTUP}

\section{A. Kesimpulan}

Kesimpulan yang dapat diambil berdasarkan penelitian yang telah dilakukan adalah sebagai berikut.

1. Berdasarkan rancangan yang telah dibuat, untuk mendapatkan tegangan 51 Volt maka resistor resistor variabel diatur sebesar $500 \mathrm{Ohm}$ sehingga mendapatkan duty cycle sebesar 0,37 atau 37\%.

2. Tegangan ideal pada proses pengisian ini didapatkan pada kondisi tegangan 51 volt dengan mempertimbangkan kapasitas tegangan masingmasing aki saat penuh yaitu sebesar 12,7 volt.

3. Dari pengaruh daya terhadap rancangan boost converter mendapat efesiensi maksimum sebesar $94 \%$ dan efesiensi minimum sebesar $77 \%$. Hal ini menunjukan bahwa perancangan sudah berjalan baik dan cukup handal untuk digunakan.

\section{B. Saran}

Ada beberapa saran yang dapat diberikan setelah melakukan penelitian ini, yaitu sebagai berikut.

1. Perlu dilakukan penelitian lanjutan untuk melihat apakah boostconverter dapat meningkatkan energi listrik yang dihasilkan.

2. Dapat dilakukan penelitian guna peningkatan daya boost converter sehingga mendapatkan efisiensi yang lebih optimum.

\section{REFERENSI}

[1] Kurniawan, Aditya. 2012. Analisi Perancangan dan Simulasi Konvertor Penaik Tegangan pada Sistem Jaringan Listrik Mikro Arus Searah. Jakarta:Universitas Indonesia.

[2] Yuwono, Budi. 2005. Optimalisasi Panel Sel Surya dengan Menggunakan Sistem Pelacak Berbasis Mikrokontroler At89c51. Surakarta: Universitas Sebelas Maret.

[3] Pandiarajan, N., and Ranganath Muthu. Mathematical Modeling of Photovoltaic Module with Simulink. India: Departement of Electrical Engineering SSn College of Engineering Kalavakkam.

[4] Aurino, Dkk. 2011. Sistem Pengisian Battery Lead Acid secara Adaptive. Surabaya: Politeknik Elektronika Negeri Surabaya. 
[5] Surja, Dkk. 2008. Switch Mode Power Supply Menggunakan Boost ConverterSebagai Pfc Converter. Surabaya: Institut Teknologi Sepuluh Nopember Surabaya.

[6] Malvino, Albert. 1986. Prinsip-Prinsip Elektronika. Jakarta: Erlangga.
[7] Prayogo, Rudito. 2012. Pengaturan PWM. Malang: Universitas Brawijaya Malang.

[8] Fathah, Abdul. 2013. Design Of a Boost Converter. Rourkela: National Institute Of Technology Rourkela. 